\title{
非晶态 $\mathrm{GeSb}_{2} \mathrm{Te}_{4}$ 薄膜在热退火过程中的 FCC 亚稳晶相和六方稳定晶相
}

\author{
薛松生范正修 干福喜 \\ (中国科学院上海光学精密机械研究所, 上海 201800)
}

关钺词 $\mathrm{GeSb}_{2} \mathrm{Te}_{4}$ 相变记录介质、FCC 亚稳相六方相、非晶态真空热退火

\section{一、引 言}

自 1970 年, Ovshinsky ${ }^{[1]}$ 首次报道利用硫系合金薄膜的可逆结构相变来进行光学数据存 贮以来, $\mathrm{Te}$ 基合金由于具有大的光吸收、低的热导率和适当的晶化特性而得到了广泛的䂰 究, 如 $\mathrm{TeGeSbS}, \mathrm{TeSeGa}, \mathrm{TeGeSnAu}, \mathrm{TeGe}, \mathrm{GeSbTe}^{\text {等 }}{ }^{[2]}$, 其中以 $\mathrm{GeSb}_{2} \mathrm{Te}_{4}$ 化合物半导 体材料最具有吸引力. Yamada ${ }^{[3]}$ 报道了 $\mathrm{GeSb}_{2} \mathrm{Te}_{4}$ 材料的光记录特性, 可用 50 (ns) 激光脉 冲檫除(使非晶记录斑点结晶), 可进行单光束重写, 其载噪比大于 $50(\mathrm{~dB})$. Yokota ${ }^{[4]}$ 研究了 $\mathrm{GeSb}_{2} \mathrm{Te}_{4}$ 薄膜的光学性质, $\mathrm{Terao}^{[2]}$ 报道了采用 $\mathrm{GeSb}_{2} \mathrm{Te}_{4}$ 为记录介质的单光束重写 技术, 但对非晶态 $\mathrm{GeSb}_{2} \mathrm{Te}_{4}$ 薄膜在热致相变过程中的结构变化尚无人进行深人的研究, 而这方面 的工作无论是作为研究光致相变机制, 还是非晶半导体的热致相变机制都是十分有意义的. 本 文报道了非晶 $\mathrm{GeSb}_{2} \mathrm{Te}_{4}$ 薄膜在热致相变过程中的晶体结构变化, 非晶 $\mathrm{GeSb}_{2} \mathrm{Te}_{4}$ 薄膜在 $130^{\circ} \mathrm{C}$ 左右转变为 FCC 亚稳晶相, $200^{\circ} \mathrm{C}$ 左右形成六方 (Hex) 晶相.

\section{二、实验方法}

非晶态 $\mathrm{GeSb}_{2} \mathrm{Te}_{4}$ 薄膜由高频磁控溅射制备. 多晶溅射靶材 $\mathrm{GeSb}_{2} \mathrm{Te}_{4}$ 由真空烧熔合成 制得. 高频频率 $13.6(\mathrm{MHz})$, 浌射时净输人功率 $200(\mathrm{~W})$, 浌射前预抽真空至 $4 \times 10^{-4} \mathrm{~Pa}$, 然后通高纯氯气 $(5 \mathrm{~N})$ 使溅射气压保持在 $5 \times 10^{-1} \mathrm{~Pa}$. 基板为 $K_{9}$ 玻璃, 溅射时不加温. 用 时间法粗控膜厚, 成膜后用多光束干涉仪精确测量薄膜的几何㙞度. 用作 $\mathrm{X}$ 光衍射的薄膜样 品厚 $1 \mu \mathrm{m}$, 从基板上取下约 $10 \mathrm{mg}$ 左右的薄膜粉末作差热分析.

为防止氧化, 在镀膜机中进行真空热退火处理. 预抽真空至 $7 \times 10^{-4} \mathrm{~Pa}$, 在一定的升温 速率下升温至设定温度后, 让其自然冷却.

在 Rigaku D/Max-IIIC X 光衍射仪和 Perkin-Elmer DSC7 型示差扫描㻎热计上分别 进行了样品的结构分析和热分析.

\section{三、结果与讨论}

\section{1. 多晶 $\mathrm{GeSb}_{2} \mathrm{Te}_{4}$ 粉末标样的 X 光衍射及结构分析 由于 ASTM 多晶粉末衍射卡}

本文 1991 年 3 月 12 日收到. 1991 年 12 月 29 日收到修改稿. 
片中无 $\mathrm{GeSb}_{2} \mathrm{Te}_{4}$ 材料的 $\mathrm{X}$ 光衍射数据, 而溥膜样品衍射峰有限, 难以进行指标化和晶体结构 分析. 因此我们首先进行多晶 $\mathrm{GeSb}_{2} \mathrm{Te}_{4}$ 粉末标样的 $\mathrm{X}$ 光衍射, 见图 1. 表 1 给出, 图 1 中衍

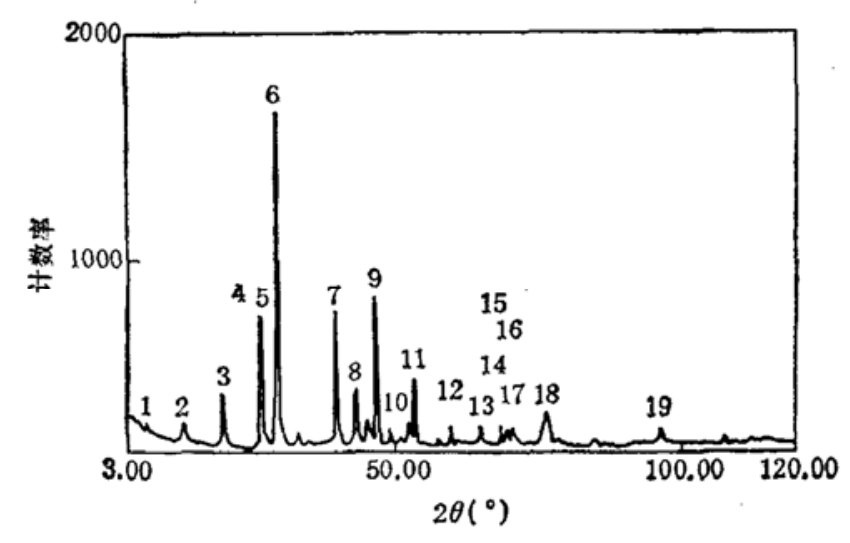

图 1 多晶 $\mathrm{GeSb}_{2} \mathrm{Te}_{4}$ 粉末标样的 $\mathrm{X}$ 谈衍射谱 射峰的指标化结果. 稳定的多晶 $\mathrm{GeSb}_{2}$ $\mathrm{Te}_{4}$ 相为六方 $(\mathrm{Hex})$ 结构, 根据指标化 结果可算得其晶格常数为: $a=4.21 \AA$, $c=40.6 \AA$.

\section{2. $\mathrm{GeSb}_{2} \mathrm{Te}_{4}$ 薄膜样品的 $\mathrm{X}$ 光衍} 射及结构分析图 2 给出了不同退火 温度下 $\mathrm{GeSb}_{2} \mathrm{Te}_{4}$ 薄膜的 $\mathrm{X}$ 光衍 射 谱. 处于沉积状态 (as-deposited) 的 $\mathrm{GeSb}_{2}$ $\mathrm{Te}_{4}$ 薄膜为非晶态, 当退火温度为 120 $160^{\circ} \mathrm{C}$ 时出现 FCC 亚稳相, 其指标化 结果见图 2.FCC $\mathrm{GeSb}_{2} \mathrm{Te}_{4}$ 相的晶格 常数 $a=6.023 \AA$. 在 $180^{\circ} \mathrm{C}$ 退火温度下 FCC 相和六方 (Hex) 相共存, $200^{\circ} \mathrm{C}$ 退火温度 表 1 多晶粉末 $\mathrm{GeSb}_{2} \mathrm{Te}$ ，标样 $\mathrm{X}$ 光衍射峰的指标化结果

\begin{tabular}{|c|c|c|c|c|}
\hline No. & $2 \theta\left(^{\circ}\right)$ & d (面间距) & $I / I_{0}$ & 晶面的密勒指数 \\
\hline 1 & 6.56 & 13.463 & 3 & 003 \\
\hline 2 & 13.02 & 6.794 & 6 & 006 \\
\hline 3 & 19.54 & 4.539 & 17 & 009 \\
\hline 4 & 26.10 & 3.411 & 41 & 0012 \\
\hline 5 & 26.72 & 3.334 & 3 & $1 \overline{15}$ \\
\hline 6 & 28.82 & 3.095 & 100 & 107 \\
\hline 7 & 39.42 & 2.284 & 42 & 0018 \\
\hline 8 & 42.84 & 2.109 & 17 & $1 \overline{10}$ \\
\hline 9 & 46.48 & 1.952 & 47 & 0021 \\
\hline 10 & 52.40 & 1.745 & 7 & $1 \overline{120}$ \\
\hline 11 & 53.60 & 1.708 & 21 & 208 \\
\hline 12 & 59.56 & 1.551 & 6 & 2014 \\
\hline 13 & 65.02 & 1.433 & 6 & 1121 \\
\hline 14 & 68.58 & 1.367 & 4 & $2 \overline{14}$ \\
\hline 15 & 68.92 & 1.361 & 5 & 2020 \\
\hline 16 & 69.80 & 1.346 & 5 & $10 \overline{28}$ \\
\hline 17 & 70.80 & 1.330 & 6 & $2 \overline{17}$ \\
\hline 18 & 76.46 & 1.245 & 10 & $10 \underline{1}$ \\
\hline 19 & 96.00 & 1.037 & 6 & $00 \underline{39}$ \\
\hline
\end{tabular}

下 FCC 相消失, 与图 1 的衍射峰比较可知此时出现六方 (Hex) 相.

3. 非晶态 $\mathrm{GeSb}_{2} \mathrm{Te}_{4}$ 薄膜样品的差热分析 图 3 给出非晶态 $\mathrm{GeSb}_{2} \mathrm{Te}_{4}$ 薄膜粉末的差 热分析.

非晶态 $\mathrm{GeSb}_{2} \mathrm{Te} \mathrm{e}_{4}$ 薄膜的玻璃软化点 $\mathrm{Tg}$ 约为 $93^{\circ} \mathrm{C}$, 在 $158^{\circ} \mathrm{C}$ 时出现第一结晶峰, 应对 应 FCC 相的出现, 在 $216^{\circ} \mathrm{C}$ 时出现第二结晶峰, 此时 FCC 相转变为 Hex 相.

在相变光记录中, $\mathrm{GeSb}_{2} \mathrm{Te}_{4}$ 薄膜具有较快的擦除（晶化）速度应源于 FCC 相的出现， FCC 相可以在非晶态 $\mathrm{GeSb}_{2} \mathrm{Te}_{4}$ 薄膜中直接形成而不必有相分离的过程. 而六方相的形 成 


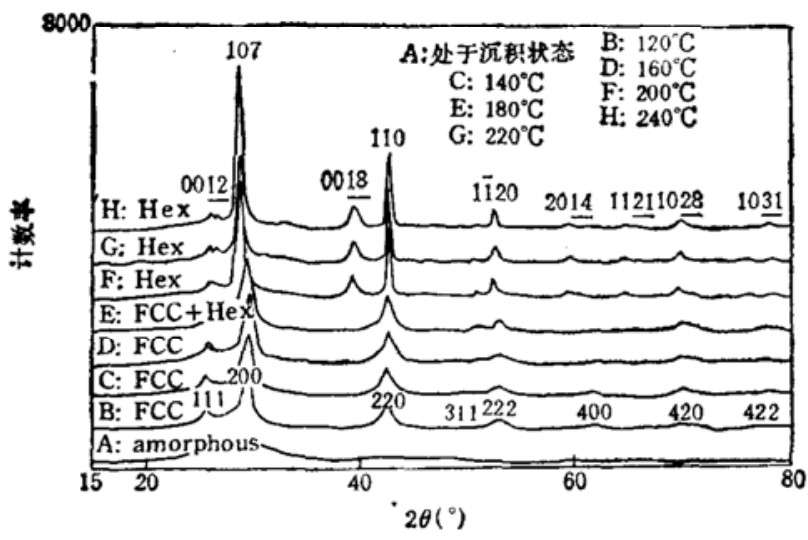

图 2 不同退火温度下 $\mathrm{GeSb}_{2} \mathrm{Te}_{4}$ 薄膜的 $\mathrm{X}$ 光衍射谱

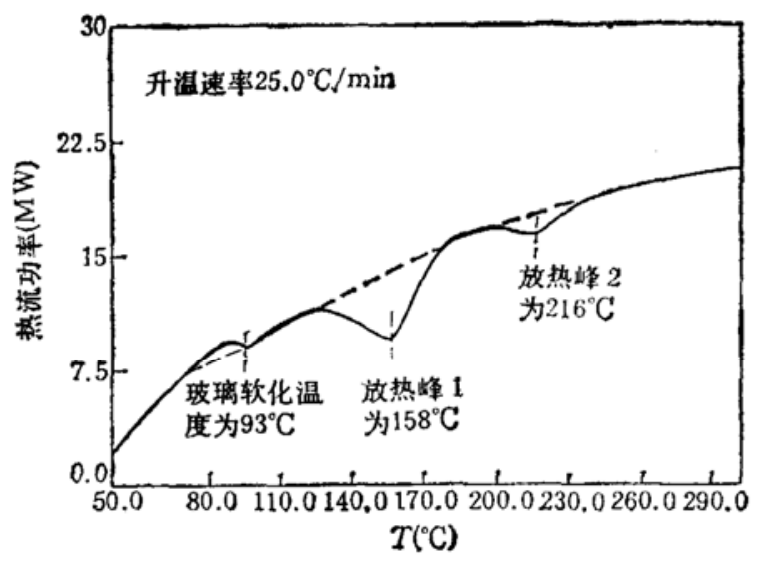

图 3 非晶态, $\mathrm{GeSb}_{2} \mathrm{Te}_{4}$ 薄膜粉末的差热分析

应需要较长的晶化时间. 因此具有快速晶化特性的相变记录介质在光擦除过程中形成的站荘 相应该具有可以高速晶化的特点,如 FCC 相,简立方等.

\section{参考文 献}

[1] Ovshinsky, S. R., J. Non-Cryst. Solids, 2(1970), 99-110.

[2] Terao, M. et al., SPIE., 1078(1989), 2-10.

[3] Yamada, N. et al., Jap. J. Appl. Phys., 26(1987), 61-69.

[4] Yokota, R., Jap. J. Appl. Pyhs., 28(1989), 1407-1411. 